04

\title{
Эффект воздействия коротковолнового УФ излучения при записи голографических структур на содержащих желатин регистрирующих средах (обзор)
}

\author{
(C) Н.М. Ганжерли ${ }^{1}$, С.Н. Гуляев ${ }^{2}$, И.А. Маурер ${ }^{1}$ \\ ${ }^{1}$ Физико-технический институт им. А.Ф.Иофффе, \\ 194020 Санкт-Петербург, Россия \\ ${ }^{2}$ Санкт-Петербургский политехнический университет Петра Великого, \\ 195251 Санкт-Петербург, Россия \\ e-mail: nina.holo@mail.ioffe.ru, Gulyaev@rphf.spbstu.ru
}

Поступила в редакцию 17.03.2018 г.

В обзоре обсуждены возможности получения высокоэффективных рельефно-фазовых структур на галоидосеребряных фотоэмульсиях и слоях бихромированного желатина с помощью облучения первоначально зарегистрированных голографических структур коротковолновым УФ излучением.

DOI: $10.21883 /$ OS.2018.07.46268.73-18

\section{Введение}

Желатин как органическое вещество хорошо поглощает УФ излучение, которое способно его разрушать. На этом основан метод деструктивного воздействия коротковолнового УФ излучения на желатин $[1,2]$, входящий в состав галоидосеребряных фотоэмульсий и бихромированного желатина (БХЖ), широко распространенных светочувствительных сред для голографии [3].

Использование высокоразрешающих голографических галоидосеребряных эмульсий, обладающих высокой чувствительностью, дает возможность применять в качестве источника излучения доступные гелий-неоновые лазеры и сократить время экспонирования при записи голограмм до секунд и долей секунды. При регистрации голографической информации на галоидосеребряных фотоматериалах после проявления и фиксирования возникает первичная амплитудная структура, имеющая низкую дифракционную эффективность, обусловленную амплитудным поглощением слоя.

В настоящее время для галоидосеребряных фотоматериалов разработан ряд технологий, используемых для преобразования первичной амплитудной голографической записи в объемно-фазовую. Наиболее распространены различные технологии прямого и обращающего отбеливания фотоэмульсий [4-8], а также SHSG-метод (Silver Halide Sensitized Gelatin) [9-13]. Однако отбеливание фотоэмульсионного слоя приводит к низкой стабильности голографической структуры к воздействию света. Кроме того, отбеленные голограммы обладают неконтролируемым дополнительным светорассеянием, вызванным наличием микрокристаллов галоида серебра в толщине фотоэмульсионного слоя. SHSG-метод связан со сложной химической обработкой фотоматериала, которая включает в себя неравновесное проявление или, другими словами, быстрое обезвоживание желатинового слоя с помощью изопропанола. Поэтому основным недостатком этого метода является чрезвычайная зависимость окончательных результатов от температуры обрабатывающих растворов, концентрации реагентов и типа используемой фотоэмульсии.

Кроме указанных выше двух методов получения объемно-фазовых голографических структур существуют также способы записи тонких рельефно-фазовых структур, которые не связаны с обязательным включением в процедуру обработки неравновесного проявления, т. е. обезвоживания изопропанолом [14]. Обычно эти методы базируются на избирательном дублении, или структурировании желатина (сшивании желатиновых молекул) в отбеливателях, содержащих бихроматы (например, отбеливатель R-10) [14-18]. Образование рельефа связано с перераспределением объемов желатина в фотоэмульсионном слое при высыхании. Эти методы позволяют получить значительно более предсказуемые и стабильные результаты. Фазовая модуляция пучка голограммой в данном случае осуществляется за счет поверхностного рельефа, глубина которого составляет обычно небольшую часть общей толщины фотоэмульсионного слоя.

\section{1. Особенности создания поверхностного рельефа на содержащих желатин светочувствительных материалах при воздействии на них коротковолнового УФ излучения}

В представленных исследованиях используется способ получения поверхностного рельефа с помощью воздействия на фотоэмульсионный слой коротковолновым УФ излучением с длиной волны менее 250-270 nm и последующего удаления (травления) желатина в водных растворах (метод ВКУФ) $[1,2]$. Образование рельефа на 


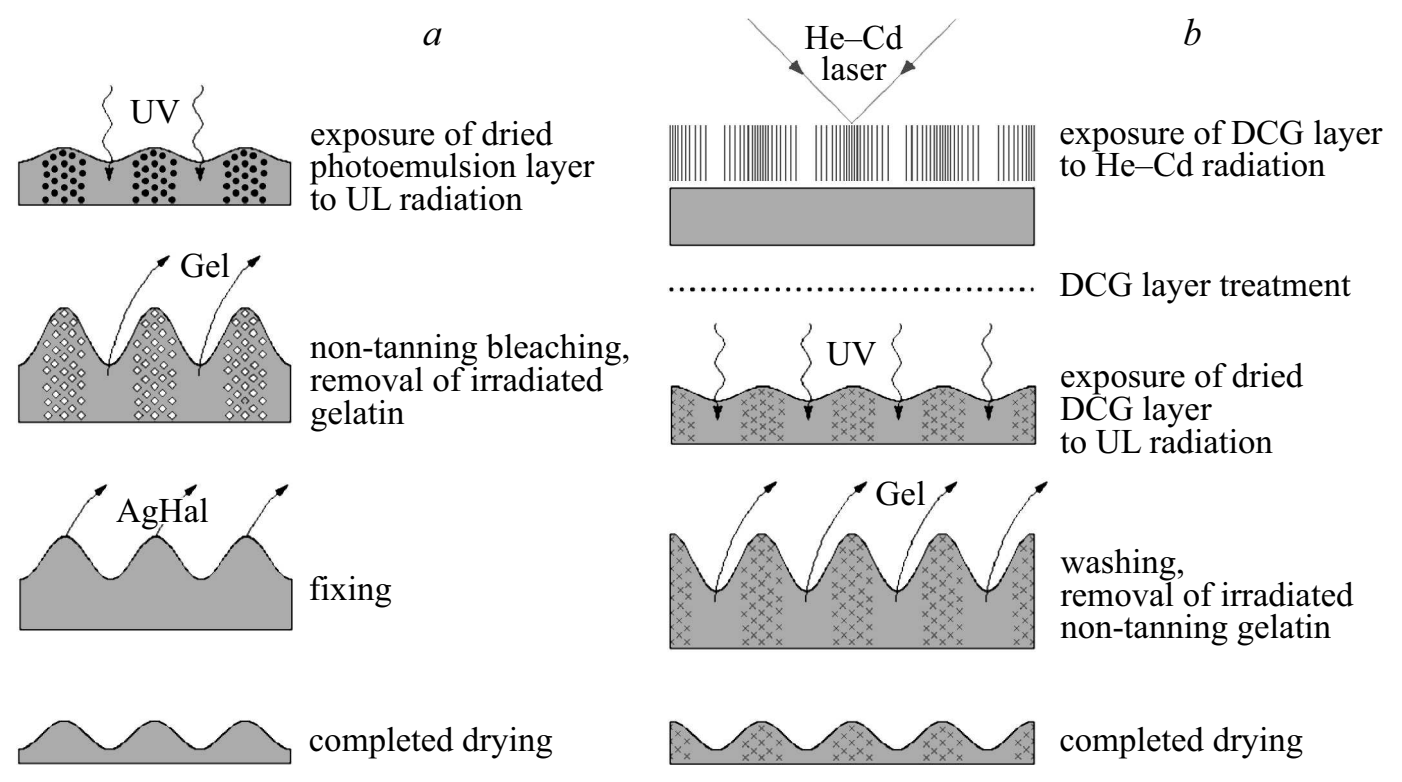

Рис. 1. Создание поверхностного рельефа с помощью деструктивного воздействия коротковолнового УФ излучения на галоидосеребряных фотоэмульсиях $(a)$ и на слоях БХЖ $(b)$.

поверхности фотоматериала по методу ВКУФ основано на свойстве желатиновых слоев изменять свою толщину при воздействии УФ излучения с последующей обработкой в воде. Количество энергии УФ излучения, поглощенного различными участками желатинового слоя, определяется оптической плотностью серебряного изображения (СИ), которое создается в фотоэмульсии за счет традиционных операций проявления и фиксирования. Участки фотоэмульсии, не содержащие СИ, поглощают УФ излучение более интенсивно и после обработки в воде и сушки приобретают меньшую толщину по сравнению с участками, где УФ излучение экранизируется СИ. Это происходит вследствие деструкции фотослоя, т.е. разрыва основных связей в цепях желатиновых молекул под воздействием коротковолнового УФ излучения. Поверхностный рельеф образуется за счет травления облученного желатина в водных растворах.

Процедура обработки по методу ВКУФ, описанная в работе [1], осуществляется по следующей схеме: экспонирование голограмм Не- $\mathrm{Ne}$ лазером - проявление фиксирование - облучение фотопластинки УФ излучением - недубящее отбеливание - фиксирование. Применение заключительных операций отбеливания и фиксирования позволяет удалить СИ из объема фотоэмульсии и получить чисто фазовые структуры (рис. 1,a). В экспериментах использовался отечественный голографический фотоматериал ПФГ-01. Обработка фотослоев ультрафиолетовым излучением осуществлялась с помощью ртутно-кварцевой лампы высокого давления ДРТ-220.

В отличие от галоидосеребряных фотоэмульсий в слоях БХЖ изменение физико-химических свойств же- латина осуществляется непосредственно при голографической записи интерференционной картины за счет избирательного светового дубления регистрирующим лазерным излучением в присутствии бихроматов (рис. 1,b). При этом происходит структурирование, т.е. установление большого количества поперечных связей в максимумах интерференционной картины. Задубленные лазерным излучением участки БХЖ менее подвержены разрушающему воздействию коротковолнового УФ излучения, поскольку большое количество поперечных связей препятствует фрагментации желатиновых макромолекул и растворению их в воде. Таким образом, горбы поверхностного рельефа на слое БХЖ после водной процедуры образуются в наиболее задубленных местах, т. е. в максимумах интерференционной картины.

\section{2. Голограммные оптические элементы на фотоматериале ПФГ-01}

\section{1. Создание голографических диффузоров}

Голографические диффузоры используются в устройствах формирования светового пучка, в жидкокристаллических дисплеях и световых экранах, в проекционных системах, в том числе системах воспроизведения голографических изображений и в других устройствах, где возникает необходимость в формировании освещающего пучка с заданными параметрами. В отличие от обычного матового стекла голографические диффузоры позволяют управлять шириной индикатрисы рассеяния света для более эффективного использования энергии.

Одним из основных факторов, определяющим рассеивающие свойства голографических диффузоров, явля- 


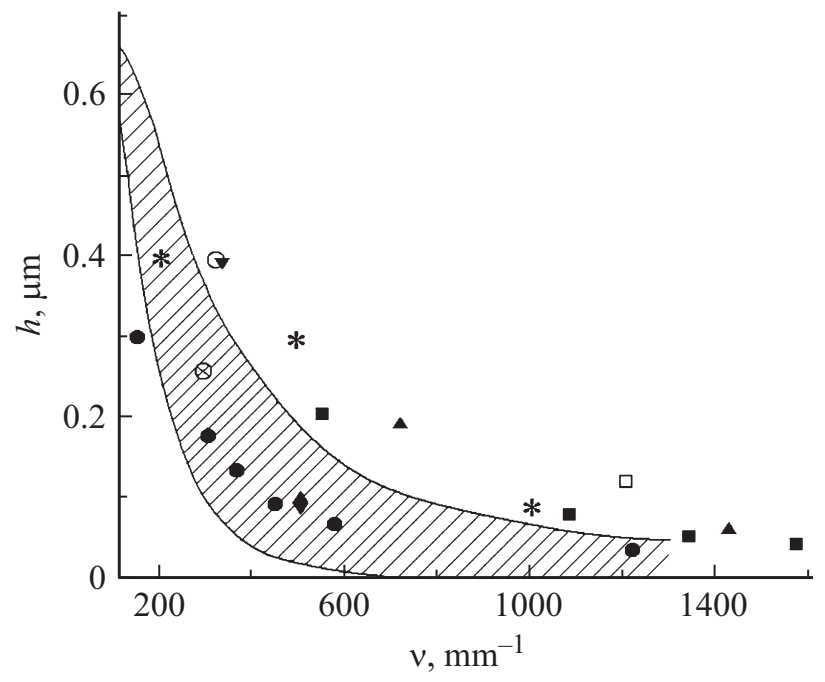

Рис. 2. Зависимость высоты поверхностного рельефа $h$ от пространственной частоты $v$ голографической структуры: для метода ВКУФ - заштрихованная область; для других методов получения чисто рельефно-фазовых голограмм на фотоэмульсиях - символы.

ется пространственно-частотная характеристика (ПЧХ) светочувствительной среды, отражающая зависимость дифракционной эффективности или высоты рельефа голографической структуры от пространственной частоты интерференционной картины. Галоидосеребряные фотоматериалы независимо от методов получения рельефно-фазовых структур имеют ограничения по передаче пространственно-частотного спектра. Это может быть теоретически объяснено сглаживающим воздействием сил поверхностного натяжения, возникающих во влажном фотоэмульсионном слое на высоких пространственных частотах [19]. Математическая модель, описывающая спад ПЧХ в области высоких частот $\left(v=200-1500 \mathrm{~mm}^{-1}\right)$ для метода получения рельефнофазовых голограмм воздействием коротковолнового УФ излучения, приведена в работе [20]. Значения глубины поверхностного рельефа в указанном диапазоне пространственных частот для метода ВКУФ хорошо согласуются с данными, полученными многими авторами как на фотоэмульсионных слоях, так и на слоях БХЖ с помощью других способов создания рельефно-фазовых структур (рис. 2) [20].

Регистрация голографических диффузоров на галоидосеребряных фотослоях проводилась по безопорной оптической схеме [21], предложенной для создания спеклэкранов на объемных слоях БХЖ (рис. 3). Область пространственных частот $v$, регистрируемых голограммой, определяется апертурой первичного диффузора $D_{1}$ согласно приближенной формуле:

$$
v_{\max } \approx d_{1} / \lambda L
$$

где $v_{\max }$ - предельная пространственная частота регистрируемой интерференционной картины, $d_{1}$ - диаметр апертуры первичного рассеивателя, $\lambda$ - длина волны лазерного излучения, $L-$ расстояние от первичного рассеивателя до регистрирующей среды $H$.

Взаимосвязь между рассеивающими характеристиками узконаправленных голографических диффузоров и параметрами оптической схемы регистрации, а также способами фотохимической обработки галоидосеребряных фотоэмульсий исследовалась в работах [22-25]. Для сравнения, кроме метода ВКУФ также использовался метод преобразования амплитудной голографической записи в рельефно-фазовую с помощью дубящего отбеливания голограмм в содержащем бихроматы отбеливателе R-10. В экспериментах регистрировались образцы голографических диффузоров при соотношениях внешнего диаметра $d_{1}$ к внутреннему $d_{2}$, равных $1.06-1.07$ (апертура в виде кольца) и $\infty$ (апертура в форме круга).

Основным итогом явилось снятие индикатрис рассеяния диффузоров при разных соотношениях между диаметром $d_{1}$ апертуры первичного рассеивателя и расстоянием $L$ от него до плоскости регистрации в случае круговой апертуры (рис. 4,a). Также снималась зависимость ширины индикатрисы рассеяния $\Delta \theta$ для круговой апертуры (рис. 4, $b$, кривая 2) и для апертуры в форме кольца (кривая 3) от относительной апертуры первичного рассеивателя $d_{1} / L[24,25]$. Кривая 1 на рис. $4, b$ показывает предельный угол рассеяния диффузора $\theta_{\max }$, соответствующий максимальной пространственной частоте, регистрируемой голограммой в соответствии с формулой (1) в линейном режиме голографической записи.

Результаты измерений показали устойчивую корреляцию между относительной величиной апертуры первичного рассеивателя $d_{1} / L$ и полушириной индикатрисы рассеяния голографического диффузора (рис. $4, b$ ), что позволяет управлять шириной индикатрисы рассеяния в широких пределах. Также оказалось, что использование кольцевой апертуры первичного рассеивателя более предпочтительно по сравнению с круговой. Это

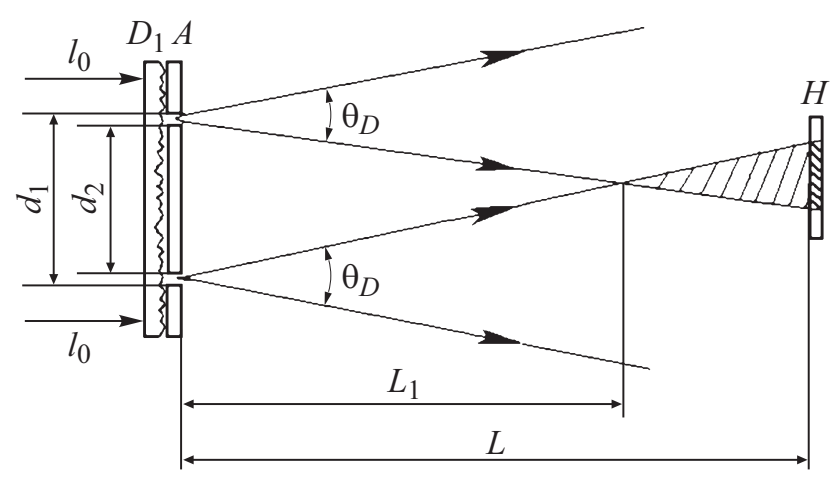

Рис. 3. Безопорная оптическая схема регистрации голографических диффузоров. $l_{0}-$ падающий пучок света, $D_{1}-$ первичный диффузор с шириной индикатрисы рассеивания $\theta_{D}$, $A$ - кольцевая апертура с внешним $d_{1}$ и внутренним $d_{2}$ диаметрами, $H-$ регистрирующая среда на расстоянии $L$ от апертуры. 


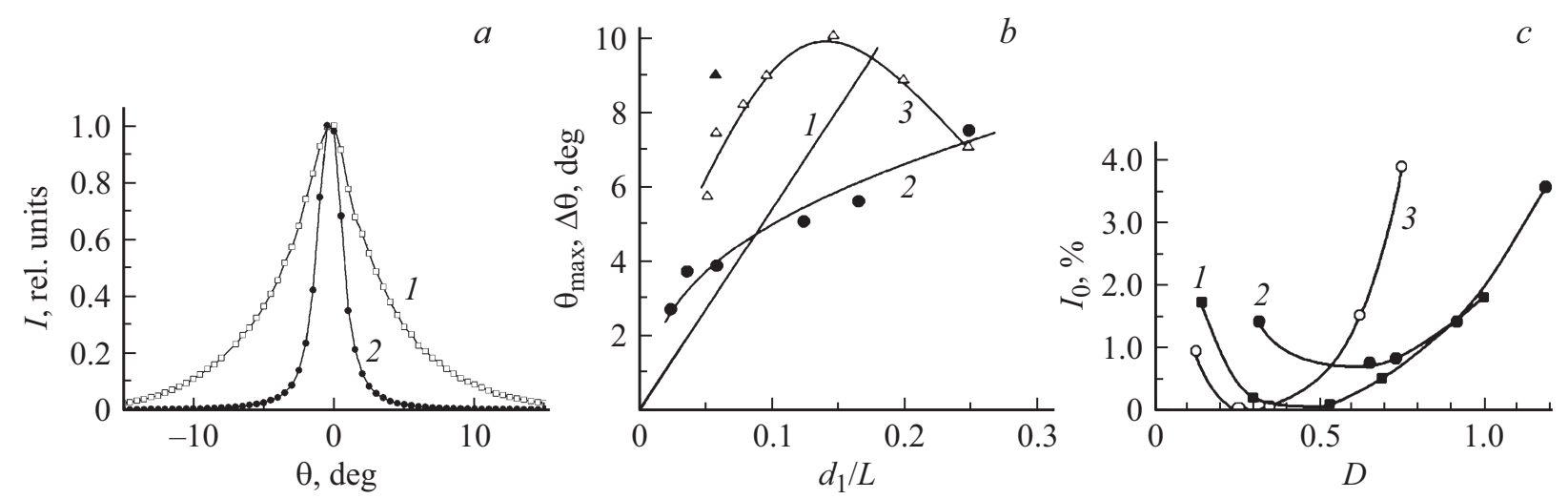

Рис. 4. Индикатрисы рассеяния голографических диффузоров для различных значений величины относительной апертуры первичного рассеивателя $d_{1} / L=0.035$ (кривая 1), 0.02 (кривая 2) (a). Зависимость предельного угла рассеяния $\theta_{\max }$ (кривая 1 ) и ширины индикатрисы рассеяния голографических диффузоров $\Delta \theta$ для круговой апертуры (кривая 2) и апертуры в форме кольца (кривая 3) от $d_{1} / L(b)$. Зависимость интенсивности нулевого порядка $I_{0}$ от средней оптической плотности СИ $D$ для голографических диффузоров, изготовленных с помощью первичного рассеивателя с различными отношениями внешнего диаметра к внутреннему диаметру $d_{1} / d_{2}=1.07$ (кривая 1$), \infty$ (кривая 2) и с помощью мультиплексной голограммы (кривая 3$)(c)$.

связано с тем, что использование апертуры в виде кольца дает возможность снизить вклад самых низких пространственных частот в регистрируемый голограммой спектр [26] и существенно уменьшить величину пропускаемого диффузором света в нулевом порядке дифракции $I_{0}$. Эксперименты с кольцевой апертурой с отношением внешнего диаметра к внутреннему порядка 1.07 показали уменьшение почти на порядок интенсивности нулевого порядка $I_{0}$ для голографических диффузоров, обработанных по методу ВКУФ (рис. 4, кривая 1), по сравнению с диффузорами, полученными при использовании круговой апертуры тем же методом (рис. 4,c, кривая 2) [24,25]. При переходе от круговой апертуры к кольцевой происходит существенное изменение топографии микроструктуры диффузора. Практическая возможность применения кольцеобразных апертур связана с тем обстоятельством, что высокая чувствительность галоидосеребряных фотоматериалов даже при использовании кольцевых апертур, задерживающих большое количество света, позволяет сохранить время экспонирования голограмм в разумных пределах.

В качестве другого способа создания голографического диффузора предложено использование мультиплексных голограмм на основе регистрации набора дифракционных решеток, повернутых друг относительно друга на небольшой угол $\delta$ [27-29]. Как известно, обычная синусоидальная амплитудная голографическая решетка создает кроме нулевого порядка дифракции только два порядка $( \pm 1)$. Таким образом, подобная решетка рассеивает падающее на нее излучение под плоским углом. Для того чтобы голограмма рассеивала падающее излучение в объемном телесном угле, необходимо, чтобы ее структура была более сложной, т. е. содержала в себе множество дифракционных решеток, ориентированных под разными углами в плоскости голограммы. Подобную структуру можно реализовать в виде тонкой амплитуд- ной голограммы, которая создается путем многократной записи интерференционной картины двух плоских пучков, сходящихся на фотопластинке под углом $\gamma$. При этом производится $N / 2$ одинаковых экспозиций, между которыми фотопластинка поворачивалась на небольшой фиксированный угол $\delta=2 \pi / N$ вокруг нормали к ее поверхности. Величина угла $\delta$ в конечном итоге определяет количество плоских волн $N$, восстанавливаемых мультиплексной голограммой.

После проявления и фиксирования фотопластинки голографическая структура мультиплексной голограммы представляет собой совокупность множества амплитудных решеток, повернутых относительно друг друга. При освещении мультиплексной голограммы каждая из элементарных решеток создает пучки \pm 1 порядков дифракции, которые в Фурье-плоскости первой линзы 7 (рис. 5) $[28,29]$ собираются в кольцо, заполненное $N$ светящимися точками (рис. $6, a)$ [28,29]. Используя режекторный кольцеобразный пространственный фильтр 8, можно подавить волну нулевого порядка дифракции и уменьшить когерентные шумы мультиплексной голограммы. Плоские волны, порожденные мультиплексной голограммой, собираются второй линзой 9 на фотопластинку 10, которая экспонируется, проявляется и фиксируется с целью получения амплитудной голограммыдиффузора.

На рис. 6, $b$ [28,29] приведен Фурье-спектр амплитудной голограммы-диффузора, который представляет собой заполненный светящимися точками круг вдвое большего диаметра по сравнению с Фурье-спектром мультиплексной голограммы (рис. 6,a), а плотность расположения светящихся точек за исключением области очень низких пространственных частот равномерна внутри круга. Это же показывает и теоретический анализ, проведенный в работе [28]. Очевидно, что плотность расположения светящихся точек в дифракцион- 


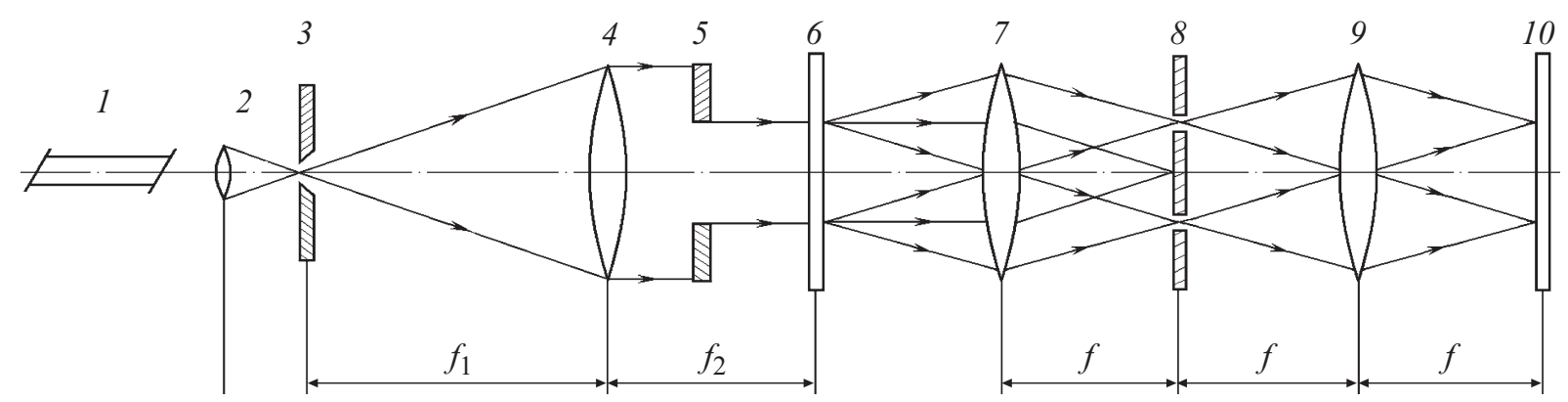

Рис. 5. Оптическая схема записи амплитудной голограммы-диффузора. 1 - Не-Ne-лазер; 2, 3, 4 - коллиматор, $5-$ диафрагма, 6 - амплитудная мультиплексная голограмма; 7,9 - линзы, 8 - пространственный фильтр, 10 - амплитудная голограммадиффузор, $f-$ фокусное расстояние линз 7,9.

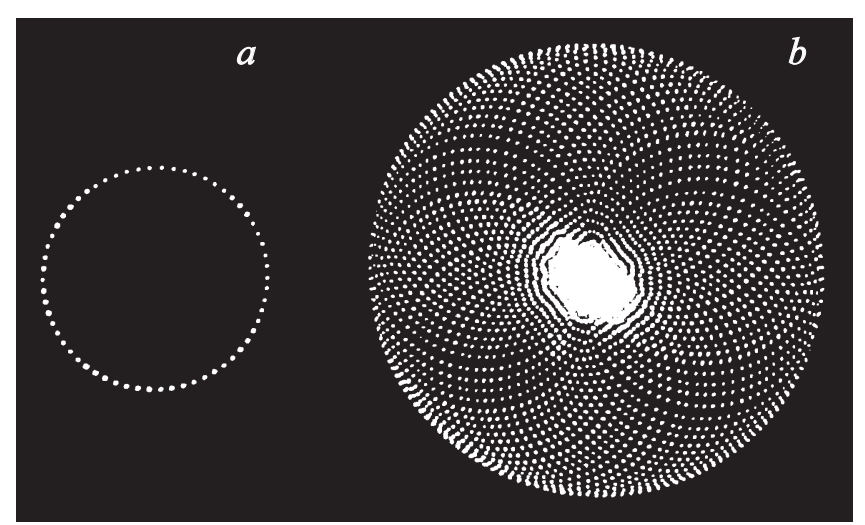

Рис. 6. Распределение интенсивности света в фокальной плоскости линзы для мультиплексной голограммы за режекторным фильтром $(a)$ и для амплитудной голограммы-диффузора $(b)$.

ной картине будет задавать оптические свойства амплитудной голограммы-диффузора, т. е. определять долю энергии рассеянного света, дифрагированного в том или ином телесном угле. При преобразовании амплитудной голограммы-диффузора в более эффективную рельефнофазовую структуру дифракционный спектр существенно изменяется хотя бы из-за того, что вследствие ярко выраженной нелинейности подобного преобразования произойдет генерация высших пространственных гармоник. При этом ширина индикатрисы рассеяния фазовой голограммы-диффузора и ее форма будут определяться, во-первых, исходным дифракционным спектром амплитудной голограммы-диффузора, поскольку он отражает наличие тех или иных пространственных частот в структуре голограммы. Во-вторых, оптические свойства фазовой голограммы-диффузора существенно зависят от самого характера нелинейного преобразования амплитудной структуры в фазовую. В наших экспериментах преобразование амплитудной голограммы-диффузора в высокоэффективную рельефно-фазовую структуру осуществлялось с помощью метода ВКУФ.

На рис. 4, с (кривая 3) [28,29] приведена зависимость относительной интенсивности нулевого поряд- ка $I_{0}$ от средней оптической плотности $D$ первичного СИ амплитудной голограммы-диффузора для угла схождения пучков при записи мультиплексной голограммы $\gamma=5.6^{\circ}$. Показано, что минимальная величина нерассеянной компоненты $I_{0}$ излучения, прошедшего через диффузор, лежит в интервале $0.05-0.07 \%$ независимо от угла схождения пучков $\gamma$. Это существенно лучше результатов для $I_{0}(0.1-0.2 \%$ от интенсивности падающего света) при синтезе голографических диффузоров по безопорной схеме с помощью стеклянных матовых рассеивателей в качестве первоначального диффузора и при использовании кольцеобразной апертуры (рис. 4, кривая 1).

Применение мультиплексной голограммы для создания диффузоров имеет определенное преимущество, поскольку позволяет существенно сократить время экспонирования фотослоя. Снижение доли нерассеянной компоненты света $I_{0}$ до сотых долей процента в более широком диапазоне изменения оптической плотности $D$ серебряного изображения амплитудной голограммыдиффузора значительно упрощает процесс изготовления высокоэффективных узконаправленных диффузоров на практике.

\section{2. Создание микролинзовых растров}

Микролинзовые растры используются в устройствах формирования светового пучка, при мультиплицировании изображений ит.д. Для создания микролинзовых растров использовалась методика, в основе которой лежит изготовление первичной двумерной амплитудной голографической структуры, полученной при регистрации картины интерференции двух плоских волн, распространяющихся под углом друг к другу. Угол схождения пучков определяет пространственную частоту голографической решетки и является одним из основных факторов, отвечающим за размер элементов растра. Необходимым этапом получения двумерной структуры является поворот фотопластинки в своей плоскости на угол $90^{\circ}$ между двумя экспозициями. После проявления и фиксирования фотоэмульсии получается скрещенная амплитудная двумерная голографическая решетка (ДГР) [30]. 
Теоретически можно показать, что вблизи любого минимума интерференционной картины распределение полной энергии света, падающего на фотопластинку за время двух экспозиций и, соответственно, коэффициент пропускания голограммы будет представлять функцию, обладающую симметрией вращения относительно координатной точки этого минимума. Если фотоматериал обработан контрастным проявителем, т.е. обладает $z$-характеристикой для коэффициента пропускания от величины экспозиции, на негативе будут наблюдаться повторяющиеся ряды круглых прозрачных апертур на почти непрозрачном фоне. В предельном случае для фотоматериала с абсолютным контрастом после проявления и фиксирования ДГР будут представлять собой матрицу круглых прозрачных апертур на темном фоне. В реальном эксперименте из-за неидеальности $z$-характеристики фотоматериала границы круглых пропускающих апертур в ходе процесса химической обработки размываются. При этом прозрачным круглым апертурам сопутствуют линзообразные впадины, поскольку толщина фотоэмульсионного слоя в местах с наименьшей плотностью СИ минимальна. Способ получения поверхностного рельефа, связанный с воздействием УФ излучения на фотоэмульсию, формирует максимальную толщину желатинового слоя в области с наибольшей плотностью СИ. Вследствие этого получение растров положительных линз непосредственно на основе ДГР, полученной обычным проявлением и фиксированием, невозможно.

Проблема решается фотографическим обращением исходной ДГР. Обращение осуществлялось с помощью засветки голографических фотопластинок ПФГ-01 через исходную матрицу круглых апертур методом контактной фотопечати. Полученные образцы облучались коротковолновым УФ излучением. Были получены прозрачные рельефные растры собирающих микролинз с фокусными расстояниями порядка $500 \mu \mathrm{m}$ и диаметрами от 35 до $90 \mu \mathrm{m}$ с небольшим коэффициентом заполнения площади $(K=0.3)$, что было обусловлено большим зазором между элементами растра (рис. 7, $a$ ) [31].

Улучшить параметры растров микролинз удалось, используя изображающие свойства ДГР [32]. ДГР в первом приближении можно рассматривать как набор из камеробскур с отверстиями диаметром $d_{A}$, способных формировать периодически повторяющееся изображение на находящейся на некотором расстоянии от ДГР светочувствительной среде. Для этого перед ДГР помещался квадратный транспарант с заданным распределением коэффициента пропускания света круговой симметрии. ДГР формировала матрицу изображений транспаранта на фоточувствительном материале, при этом элементы изображения располагались встык, без зазора.

В описанных выше примерах получения микролинзовых растров использовались ДГР, прозрачные апертуры которых были сформированы в результате обычного проявления и фиксирования фотоэмульсии. Как показано в работе [32], в этом случае круглым апертурам соответствуют линзообразные впадины, поскольку толщина фотоэмульсионного слоя в местах с наименьшей плотностью СИ минимальна. Такая ДГР содержит рассеивающие микролинзы, что ухудшает ее изображающие свойства. Использование метода светового дубления желатина в присутствии бихроматов, введенного в галоидосеребряную голографию Пеннингтоном и др. [33], приводит к существенному уменьшению кривизны рассеивающих линз ДГР. Однако этим методом не удается получить собирающие линзы.

Для формирования собирающих линз, совмещенных с круглыми апертурами ДГР, был предложен вариант обработки фотоэмульсионного слоя без операции фиксирования, состоящий из следующих этапов: экспонирование фотопластинок ПФГ-01 когерентным светом с целью формирования ДГР - проявление ДГР в контрастном проявителе Д-19 - стоп-ванна на основе раствора уксусной кислоты - длительная промывка - сушка в темноте [32]. В результате такой обработки в местах круглых апертур был сформирован выпуклый рельеф, связанный с наличием в этих областях непроявленного галоида серебра $\mathrm{AgBr}$, занимающего больший объем, чем восстановленное серебро в местах с наибольшей оптической плотностью.

Исследование и анализ полученных таким способом образцов ДГР с помощью интерферометра МИИ-4 показали существенное улучшение изображающих свойств ДГР. В центре пропускающих апертур были получены микролинзы с фокусным расстоянием $170 \mu \mathrm{m}$ и диаметром пятна рассеяния в фокальной плоскости $14.1 \mu \mathrm{m}$. При этом светосила микролинзы обусловлена не формой выпуклого рельефа, а распределением показателя преломления вследствие наличия непроявленного галоида серебра $\mathrm{AgBr}$ в фотоэмульсионном слое. Используя изображающие свойства ДГР, изготовленных с помощью обычного проявления и фиксирования и обработки без фиксирования с последующим применением метода ВКУФ, удалось получить растры микролинз с высоким коэффициентом заполнения $K$ (рис. 7, b, c, d) [31,32].

\section{3. Создание голографических структур на слоях БХЖ}

\section{1. Формирование рельефно-фазовых дифракционных решеток на БХЖ}

В основе создания рельефно-фазовой структуры на БХЖ служит избирательное воздействие коротковолнового УФ излучения на слой БХЖ с переменной степенью задубленности, сформированной в результате записи интерференционной структуры голограммы лазерным пучком. В качестве объекта исследований были выбраны голографические дифракционные решетки с пространственной частотой от 60 до $220 \mathrm{~mm}^{-1}$, которые регистрировались по симметричной оптической схеме 

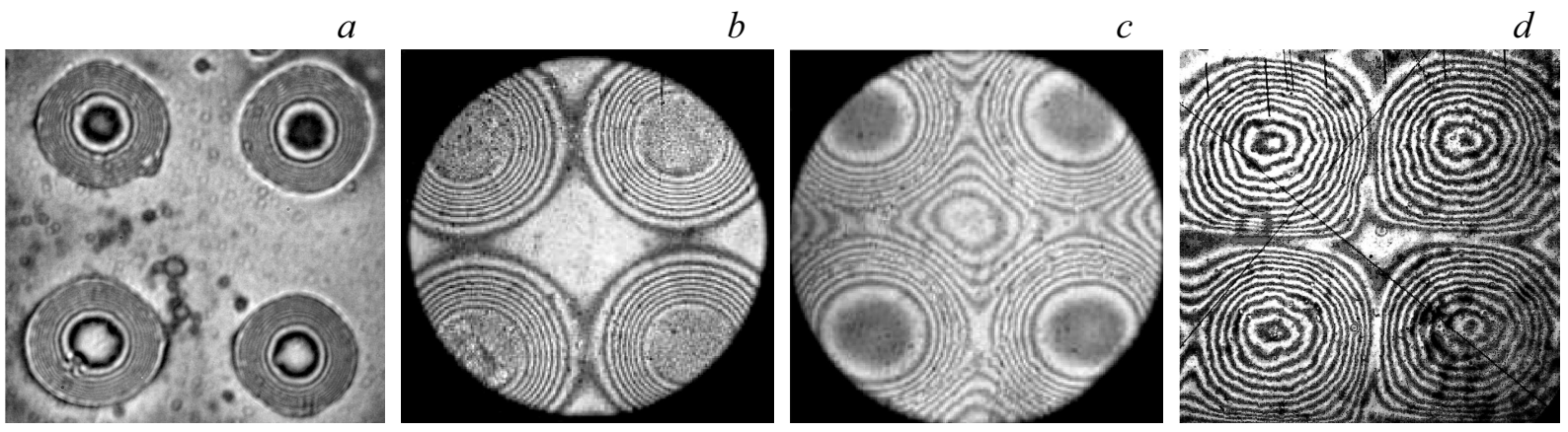

Рис. 7. Интерферограммы участков микролинзовых растров, изготовленные разными способами: с помощью контактной печати с $K=0.3(a)$; с помощью ДГР, полученной проявлением и фиксированием с $K=0.7(b), 0.76(c)$; и с помощью ДГР, изготовленной по методике проявления без фиксирования $(d)$.

на слоях БХЖ излучением Не-Сd-лазера с длиной волны $0.44 \mu \mathrm{m}$ и мощностью $12 \mathrm{~mW}$.

Слои БХЖ изготавливались в лабораторных условиях с использованием способа, подобного описанному в работе [34]. Такой подход позволил варьировать толщину полученных слоев и концентрацию бихромата аммония в нем. На горячую стеклянную подложку поливался нагретый 6\%-ный водный раствор желатина с концентрацией бихромата аммония от 0.4 до $1.2 \mathrm{~g}$ на $100 \mathrm{ml}$ раствора. Толщина высушенных слоев составляла от 1 до $90 \mu \mathrm{m}$.

Поскольку эффективное поглощение желатином УФ излучения в коротковолновой области спектра с длиной волны менее 250-270 nm ограничено узким приповерхностным слоем [35], то начальная толщина слоев БХЖ может быть снижена до величин, ненамного превышающих высоту рельефа $h$, которая необходима для получения высокоэффективных дифракционных структур в видимом диапазоне спектра $(h=0.4-0.6 \mu \mathrm{m})$. С целью получения тонких равномерных слоев БХЖ производилось предварительное разбавление первоначального 6\%-ного раствора желатина с содержанием бихромата аммония $0.4 \mathrm{~g}$ на $100 \mathrm{ml}$ раствора в 10 раз. После высыхания толщина слоев в зависимости от количества нанесенного раствора составляла от 1 до $5 \mu \mathrm{m}$.

В ходе экспонирования решеток в слое БХЖ происходило фотолитическое избирательное задубливание желатина за счет образования комплексов $\mathrm{Cr}^{3+}$. После экспонирования образцы обрабатывались в $2 \%$-ном растворе сульфита натрия $\mathrm{Na}_{2} \mathrm{SO}_{3}$ в течение 5 min для завершения процессов дубления желатина и удаления соединений хрома из слоя БХЖ. Далее следовала окончательная промывка в течение $20 \mathrm{~min}$ в проточной воде и сушка при комнатной температуре. Обработка слоев УФ излучением заключалась в облучении образцов с помощью ртутно-кварцевой лампы ДРТ-220 на расстоянии 5-10 cm, промывке в воде с температурой не более $20^{\circ} \mathrm{C}$ и сушке при комнатной температуре. Высота поверхностного рельефа в образцах решеток измерялась с помощью микроинтерферометра МИИ-4 до и после воздействия УФ излучения как перепад между гребнями и впадинами интерференционной полосы.

Облучение УФ излучением слоев БХЖ с записанными на них голографическими структурами с последующей обработкой в воде приводит к удалению фотодеградированных участков желатина преимущественно из мест с наименьшей степенью задубленности, которые соответствуют минимумам интерференционной картины (рис. $1, b)$. В работах $[36,37]$ было установлено, что воздействие УФ излучения приводит к 10-кратному увеличению высоты поверхностного рельефа структур, зарегистрированных как на толстых $\left(T_{\mathrm{avr}} \geq 50 \mu \mathrm{m}\right)$, так и на тонких $\left(T_{\mathrm{avr}} \leq 3 \mu \mathrm{m}\right)$ слоях. На сверхтонких слоях БХЖ со средней толщиной $T_{\text {avr }}<0.7 \mu \mathrm{m}$ удалось получить голографические решетки с дифракционной эффективностью (ДЭ) 30\%, приближающейся к теоретическому пределу для тонких рельефно-фазовых голограмм. При этом было установлено, что при переходе от толстых к сверхтонким слоям энергетическая чувствительность БХЖ практически не изменяется. Также было показано [37], что увеличение времени облучения коротковолновым УФ излучением сверхтонких слоев $\left(T_{\mathrm{avr}}<1 \mu \mathrm{m}\right)$ или многократное повторение цикла УФ облучение-промывка-сушка в отношении слоев средней толщины $\left(T_{\mathrm{avr}}<6 \mu \mathrm{m}\right)$ ведет к образованию окон в слое, в области которых толщина слоя БХЖ $T \rightarrow 0$.

\section{2. Перенос голографической структуры со слоя БХЖ на ПММА}

Установленная в работе [37] возможность формирования окон позволила использовать слой БХЖ подобно фоторезисту в фотолитографии и осуществить перенос голографической структуры непосредственно на подложку из органического материала, имеющего достаточную чувствительность к коротковолновому УФ излучению [38]. В качестве такого материала подложки был выбран полиметилметакрилат (ПММА).

ПММА как промышленный материал широко доступен, легко обрабатываем и имеет высокую прозрачность, 
что позволяет изготавливать из него самые разнообразные оптические элементы. Он обладает достаточно высокой чувствительностью к различного рода излучениям, что предопределило его широкое использование как резиста для электронно-лучевой литографии и рентгеновской литографии с высоким разрешением $[39,40]$. ПММА также применяется в качестве позитивного фоторезиста для коротковолнового УФ излучения $(\lambda \leq 300 \mathrm{~nm})[41,42]$, т.е. в области спектра излучения ртутных ламп, которые применялись для облучения образцов в работах [36-38].

Перенос голографической структуры на поверхность подложки из органического материала осуществляется последовательным применением технологии обработки слоев БХЖ и технологии обработки фоторезистов. Использование БХЖ в данном случае оправдано, поскольку энергетическая чувствительность материала лежит в пределах 50-500 mJ/ $\mathrm{cm}^{2}$ для видимого диапазона длин волн $\lambda=0.44-0.63 \mu \mathrm{m}$ [43], в котором существуют высококачественные когерентные источники излучения, использующиеся в голографии. Энергетическая чувствительность ПММА в диапазоне коротковолнового УФ излучения с $\lambda \leq 270 \mathrm{~nm}$ составляет $\geq 250 \mathrm{~mJ} / \mathrm{cm}^{2}$ [40], где использование лазеров для голографии ограничено вследствие низкой степени когерентности излучения и дороговизны оптических элементов.

Получение первичной голографической структуры производилось аналогично описанному в разделе 3.1. После избирательного задубливания желатина при экспонировании слоев БХЖ лазерным излучением, обработки в растворе сульфита натрия, промывки и сушки производилась процедура облучения образцов УФ излучением ртутно-кварцевой лампы ДРТ-220 в течение 7-50 min c последующей промывкой в воде и сушкой. В результате этих операций незадубленные участки желатинового слоя, находившиеся в минимумах интерференционной картины, подвергались фотолизу и удалялись растворением в воде комнатной температуры, что позволяло сформировать в слое БХЖ окна для последующего воздействия УФ излучения на материал подложки ПММА. Для относительно толстых слоев БХЖ (несколько микрон) операция засветка УФ излучением + купание в воде повторялась неоднократно, раз за разом понижая среднюю толщину слоя, чтобы обеспечить доступ УФ излучения к материалу подложки.

Последняя стадия обработки заключала в себе механическое удаление с поверхности подложки остатков желатиновых слоев, предварительно размоченных в горячей воде при температуре $45^{\circ} \mathrm{C}$ и обработку собственно ПММА. Следует отметить, что в отличие от слоев БХЖ, в которых фотодеградированные участки желатина вымываются водой, разрушенные УФ излучением участки ПММА требуют специальных травящих составов - проявителей. В литографии для резистов на основе ПММА наиболее сильным проявителем является чистый метилизобутилкетон (МИБК). Также используются смеси „МИБК + изопропанол“ в соотношении
$1: 3$, чистый изопропанол, смесь изопропанол + вода в соотношении 1:1, ацетон и др. [39,40,42,44,45]. В экспериментах использовались все вышеперечисленные составы специальных проявителей для резистов на основе ПММА. Время проявления составляло 20-120 s. После операции проявления следовала промывка в двух ваннах чистого изопропанола.

Далее измерялись такие параметры голографических решеток, как высота поверхностного рельефа и ДЭ в 1-м и 0-м порядках дифракции. ДЭ определялась как отношение интенсивности пучка того или другого порядка дифракции, прошедшего через голограмму, к интенсивности падающего пучка для длины волны Не-Ne-лазера $0.63 \mu \mathrm{m}$.

Наилучшие результаты получены при использовании проявителя МИБК, разбавленного изопропанолом в соотношении 1:1 при времени проявления порядка $20 \mathrm{~s}$. При этом были сформированы правильные регулярные рельефные структуры, обладающие высокой ДЭ в 1-м порядке до 25\% и малой долей нерассеянного света (0-й порядок) порядка 1.7\%. Высота поверхностного рельефа проявленных подложек ПММА в несколько раз превысила эту величину для непроявленных образцов, что доказало целесообразность применения проявителя, содержащего МИБК.

\section{Заключение}

Исследования, отраженные в настоящем обзоре, показали эффективность использования деструктивного воздействия коротковолнового УФ излучения на голографические регистрирующие среды на основе желатина. В результате использования специальных оригинальных методик регистрации оптической информации и способов обработки светочувствительных материалов созданы разнообразные рельефно-фазовые регулярные и случайные голографические структуры с управляемыми параметрами.

\section{Список литературы}

[1] Гуляев С.Н., Ратушный В.П. // Оптический журн. 2003. T. 70. № 2. C. 45; Gulyaev S.N., Ratushnyi V.P. // J. Opt. Technol. 2003. V. 70. N 2. P. 105. doi 10.1364/JOT.70.000105

[2] Gulyaev S.N., Isaev I.V. // Proceedings of SPIE. 2001. V. 4348. P. 59.

[3] Барачевский В.А. // Оптика и спектр. 2018. Т. 124. № 3. C. 371. doi 10.21883/OS.2018.03.45659.238-17

[4] Neipp C., Pascual I., Beléndez A. // Appl. Opt. 2002. V. 41. N 20. P. 4092.

[5] Ulibarrena M., Carretero L., Madrigal R., Blaya S., Fimia A. // Optics Express. 2003. V. 11. N 25. P. 3385.

[6] Bányász I. // Optics Commun. 2003. V. 225. P. 269.

[7] Bányász I. // Appl. Phys. Lett. 2003. V. 83. N 21. P. 4282.

[8] Лим С.В., Чой Д.В., Сон С.X. // Оптический журн. 2004. T. 71. № 1. C. 30; Lim S.V., Choy D.V., Son S.Kh. // J. Opt. Technol. 2004. V. 71. N 1. P. 26. 
[9] Kim J.M., Choi B.S., Kim S.I., Kim J.M., Bjelkhagen H.I., Phillips N.J. // Appl. Opt. 2001. V. 40. N 5. P. 622.

[10] Kim J.M., Choi B.S., Choi Y.S., Kim J.M., Bjelkhagen H.I., Phillips N.J. // Appl. Opt. 2002. V. 41. N 8. P. 1522.

[11] Усанов Ю.Е., Шевцов М.К. // Оптика и спектр. 1990. Т. 69. № 1. C. 183.

[12] Усанов Ю.Е., Шевцов М.К., Кособокова Н.Л., Кириенко E.A. // Оптика и спектр. 1991. Т. 71. № 4. С. 651.

[13] Neipp C., Márquez A., Pascual I., Beléndez A. // J. Opt. A: Pure Appl. Opt. 2003. V. 5. P. S183.

[14] Smith H.M. // J. Opt. Soc. Am. 1968. V. 58. N 4. P. 533.

[15] Бруй Е.Б., Корешев С.Н. // Оптика и спектр. 1989. Т. 67. № 3. C. 685.

[16] Гальперн А.Д., Калинина И.В., Селявко Л.В., Смаев В.П. // Оптика и спектр. 1986. Т. 60. № 5. С. 1040.

[17] Ecevit F.N., Alaçakir A., Aydin R. // Appl. Opt. 1996. V. 35. N 31. P. 6227.

[18] Navarrete-Garcia E., Calixto S. // Optical Materials. 2003. V. 23. P. 501.

[19] Бутусов М.М., Иоффе А.И. // Квантовая электроника. 1976. T. 3. № 5. С. 969.

[20] Гуляев С.Н. // Дис. канд. физ.-мат. наук. СПб: СПб ГПУ, 2005. $196 \mathrm{c}$.

[21] Ганжерли Н.М., Денисюк Ю.Н., Маурер И.А., ЧерHblх Д.Ф. // ЖТФ. 2005. Т. 75. № 2. С. 135; Ganzherl N.M., Denisyuk Y.N., Maurer I.A., Chernykh D.F. // Tech. Phys. 2005. V. 50. N 2. P. 274. doi $10.1134 / 1.1866449$

[22] Ганжсерли Н.М., Гуляев С.Н. // Оптический журн. 2007. T. 74. № 9. C. 56; Ganzherli N.M., Gulyaev S.N. // J. Opt. Technol. 2007. V. 74. N 9. P. 622. doi 10.1364/JOT.74.000622

[23] Ганжерли Н.М., Гуляев С.Н., Маурер И.А. // Химия высоких энергий. 2008. Т. 42. № 4. С. 41; Ganzherli N.M., Gulyaev S.N., Maurer I.A. // High Energy Chemistry. 2008. V. 42. N 7. P. 540. doi $10.1134 / \mathrm{S} 0018143908070114$

[24] Ганжерли Н.М., Гуляев С.Н., Гурин А.С., Крамущенко Д.Д., Маурер И.А., Черных Д.Ф. // ЖТФ. 2009. Т. 79. № 7. С. 76; Ganzherli N.M., Gulyaev S.N., Gurin A.S., Kramushchenko D.D., Maurer I.A., Chernykh D.F. // Tech. Phys. 2009. V. 54. N 7. P. 1002. doi 10.1134/S1063784209070123

[25] Ganzherli N.M., Gulyaev S.N., Maurer I.A., Chernykh D.F. // Proceedings of SPIE. 2009. V. 7358. P. 735817.

[26] О’Нейл Э. Введение в статистическую оптику. М.: Мир, 1966. C. 151-152.

[27] Ганжерли Н.М., Гуляев С.Н., Маурер И.А., Черных Д.Ф. // Мир голографии. 2013. Т. 1. № 1. С. 35. [Электронный ресурс] Режим доступа: http://www.holography-journal.com/wp-content/themes/ /eCommerce/Files/W_H_vol1_N1.pdf

[28] Ганжерли Н.М., Гуляев С.Н., Маурер И.А., Черных Д.Ф. // ЖТФ. 2014. Т. 84. № 12. С. 112; Ganzherli N.M., Gulyaev S.N., Maurer I.A., Chernykh D.F. // Technical Physics. 2014. V. 59. P. 1849.

[29] Ганжерли Н.М., Гуляев С.Н., Маурер И.А., Черных Д.Ф. // Оптический журн. 2015. Т. 82. № 3. С. 37; Ganzherli N.M., Gulyaev S.N., Maurer I.A., Chernykh D.F. // J. Opt. Technol. 2015. V. 82. N 3. P. 158.

[30] Ганжерли Н.М., Гуляев С.Н., Гурин А.С., Крамущенко Д.Д., Маурер И.А., Черных Д.Ф. // Оптический журн. 2009. Т. 76. № 7. С. 16; Ganzherli N.M., Gulyaev S.N., Gurin A.S., Kramushchenko D.D., Maurer I.A., Chernykh D.F. // J. Opt. Technol. 2009. V. 76. N 7. P. 388. doi 10.1364/JOT.76.000388
[31] Ganzherli N.M., Gulyaev S.N., Maurer I.A., Sotnikova G.Yu., Chernykh D.F. // Proceedings of SPIE. 2011. V. 8074. P. 80740T-1.

[32] Ганжсерли Н.М., Гуляев С.Н., Маурер И.А., Черных Д.Ф., Яловик С.А. // ЖТФ. 2012. Т. 82. № 9. С. 49; Ganzherli N.M., Gulyaev S.N., Maurer I.A., Chernykh D.F., Yalovik S.A. // Tech. Phys. 2012. V. 57. N 9. P. 1230. doi 10.1134/S1063784212090101

[33] Pennington K.S., Harper J.S., Laming F.P. // Appl. Phys. Lett. 1971. V. 18. N 3. P. 80.

[34] Shankoff T.A. // Appl. Opt. 1968. V. 7. P. 2101-42105. doi 10.1364/AO.7.002101

[35] Козаков О.Н., Кулипанов С.А. // Журн. научн. и прикл. фотографии. 1994. Т. 39. № 1. С. 17.

[36] Ганжерли Н.М., Гуляев С.Н., Маурер И.А. // Письма в ЖТФ. 2016. Т. 42. № 19. С. 26; Ganzherli N.M., Gulyaev S.N., Maurer I.A. // Technical Physics Lett. 2016. V. 42. N 10. P. 988. doi 10.1134/S1063785016100060

[37] Ганжерли Н.М., Гуляев С.Н., Маурер И.А. // Оптический журн. 2017. T. 84. № 9. С. 1; Ganzherli N.M., Gulyaev S.N., Maurer I.A. // Optical Technology. 2017. V. 84. N 9. P. 617. doi 10.1364/JOT.84.000617

[38] Ганжерли Н.М., Гуляев С.Н., Маурер И.А., Хазвалиева Д.Р. // ОПтика и спектр. 2018. Т. 124. № 3. C. 400; Ganzherli N.M., Gulyaev S.N., Maurer I.A., Khazvalieva D.R. // Optics Spectrosc. 2018. V. 124. N 3. P. 408. doi 10.21883/OS.2018.03.45660.246-17

[39] McCord M.A., Rooks M.J. // Handbook of Microlithography, Micromachining and Microfabrication / Ed. by P. RaiChoudhury. V. 1: Microlithography. Ch. 2. Electron Beam Lithography. Bellingham, Washington: SPIE Optical Engineering Press. 1997. P. 139. doi 10.1117/3.2265070

[40] Моро У. Микролитография. М.: Мир, 1990. В 2-х частях. М.: Мир, 1990. 605+632 c.

[41] Haiducu M., Rahbar M., Foulds I.G., Johnstone R.W., Sameoto D., Parameswaran M. // J. Micromech. Microeng. 2008. V. 18. N 11. P. 115029. doi 10.1088/0960-1317/18/11/115029

[42] Johnstone R.W., Foulds I.G., Parameswaran M. // J. Vac. Sci. Technol. B. 2008. V. 26. N 2. P. 682. doi $10.1116 / 1.2890688$

[43] Гуляев С.Н. Фазовые голограммы на галоидосеребряных фотоматериалах. 2007. С. 168. [Электронный ресурс] Режим доступа: http://www.ioffe.ru/loeg/denisyuk_seminar.html

[44] Rooks M.J., Kratschmer E., Viswanathan R., Katine J., Fontana R.E. Jr., MacDonald S.A. // J. Vacuum Sci. Technol. B. 2002. V. 20. N 6. P. 2937. doi 10.1116/1.1524971

[45] Hoole C.F., Welland M.E., Broers A.N. // Semiconductor Sci. Technol. 1997. V. 12. N 9. P. 1166. doi 10.1088/0268-1242/12/9/017 